Radioprotection, vol. 44, $\mathrm{n}^{\circ} 5$ (2009) 913-918

(C) EDP Sciences, 2009

DOI: $10.1051 /$ radiopro/20095163

\title{
A unified Ecological Risk Assessment on freshwaters for chemical and radiological ecotoxicity: The uranium case
}

\author{
K. Beaugelin-Seiller ${ }^{1}$, J. Garnier-Laplace ${ }^{2}$, R. Gilbin ${ }^{3}$ and C. Adam ${ }^{3}$ \\ ${ }^{1}$ Institut de Radioprotection et de Sûreté Nucléaire (IRSN), Laboratoire de Modélisation \\ Environnementale, Bât. 159, Centre de Cadarache, BP. 3, 13115 St. Paul-les-Durance, \\ France \\ ${ }^{2} I R S N$, Service d'Étude du Comportement des Radionucléides dans les Écosystèmes, \\ same address \\ ${ }^{3}$ IRSN, Laboratoire de Radioécologie et d'Écotoxicologie, Bât. 186, same address
}

\begin{abstract}
The classic ERA method is today recognised as relevant for both chemicals and radionuclides. As uranium presents the double ecotoxicity, a unique method may then now be applied to evaluate in tandem the associated ecological risks, following the classic four steps methodology (problem formulation, effect and exposure analysis, risk characterisation [1]). The approach is developed for freshwater ecosystems receiving ore mining releases, exposed to uranium as a chemical element and as the radioactive families of its isotopes 234, 235 and 238. The structure and the function of the ecosystem are described by a conceptual model on which both the exposure and the effect analysis are based. Species Sensitivity Distributions are applied (1) to the chemotoxicity data, to estimate a Predicted-No-Effect-Concentration for uranium in water (in $\mu \mathrm{g} / \mathrm{L}$ ); (2) to radiotoxicity effect data, to estimate a Predicted No-Effect-Dose-Rate (in $\mu \mathrm{Gy} / \mathrm{h}$ ). The risk is assessed at first through the risk quotient approach, a screening method involving for the radiological aspect back calculation of the water limiting concentration from the PNEDR for each isotope taken into account. When significant, the assessment is refined applying probabilistic techniques. The whole approach applicability was tested on a real case-study related to a former uranium mining site.
\end{abstract}

\section{INTRODUCTION}

As there is no scientific reason to discriminate between chemicals and radioactive substances in terms of environmental risk assessment methodology (ERA), it is now generally recognised [2] that the classical ERA method [1] may be applied to both of these substances. This is of particular interest in the case of uranium that presents a double ecotoxicity, chemical and radiological, leading until now to separate environmental impact and risk assessments that did not provide a global view of the ecological state of the target ecosystem. It is therefore more effective and more efficient to apply a single method to evaluate the ecological risk due to both potential chemotoxicity and radiotoxicity of uranium, following the classical four-step methodology (problem formulation, effect and exposure analysis, risk characterisation [1]).

Uranium is naturally occurring in the environment, but its distribution may be influenced by human activities, such as coal and phosphate industries, military application or nuclear fuel cycle. As a consequence of these activities, freshwater ecosystems may constitute the final receptor areas of uranium to which they may be chronically exposed both to its chemical [3-5] and radiological [6-8] ecotoxicity. We previously presented the outline of the proposed approach [9] which we have further developed for freshwater ecosystems exposed to uranium as a chemical element [1] and as the radioactive families of its three isotopes 234,235 and 238 [10] from ore mining releases. The structure and the function of the ecosystem are described by a conceptual model on which both the exposure and the effect analysis are based, using as far as possible common models and parameters for chemical an radiological risk assessment. There is however a need to adjust the current approach, particularly regarding effect 
analysis: radionuclide effects depend on the amount of radiation energy absorbed by the body of the exposed organism while chemical effects are directly linked to their concentration in the exposure medium. The necessary adaptations are described below.

Species Sensitivity Distributions (SSD) were built from (1) ecotoxicity data sets illustrating uranium chemotoxicity, allowing the estimation of a Predicted-No-Effect-Concentration (PNEC) for uranium in water expressed in $\mu \mathrm{g} / \mathrm{L}$; (2) radiotoxicity effect data, as it was done within the ERICA project, allowing the estimation of a Predicted No-Effect-Dose-Rate (PNEDR, in $\mu \mathrm{Gy} / \mathrm{h}$; [11]). The risk is assessed at first through the risk quotient approach. When significant, the assessment is refined applying probabilistic techniques. This integrative approach was applied on a real case-study related to a former uranium mining site.

\section{STEP 1: PROBLEM FORMULATION}

The first stage of any standard ERA is the problem formulation, which deals with the characterisation of the contaminant source term that should be as inclusive as possible. The potential ecological targets and the associated pollutant pathways are also described here, in order to obtain the corresponding conceptual exposure model to use for the following steps of the assessment.

From the chemical standpoint, the source term includes only the element U. In contrast, from the radiological standpoint, the situation is more complex, as natural uranium includes three radioisotopes, ${ }^{238} \mathrm{U},{ }^{235} \mathrm{U},{ }^{234} \mathrm{U}$, in known proportions, that produce by radioactive decay daughter products. All of these isotopes have the same ecotoxicological mode of action, linked to the radiation they emit and thus need to be taken into account for a realistic radiological risk assessment. However, the exercise is constrained by ecological relevance, regarding the occurrence of the radioisotopes in the exposure media (branching ratios greater than 0.9) and the organism life spans (radioisotope half life greater than half an hour).

Using a theoretical approach, a typical temperate river ecosystem has been defined in which each trophic level, each habitat and each life history strategy is represented by a model species, to describe every potential exposure pathway (Fig. 1).

\section{STEP 2: EFFECT ANALYSIS}

The effect analysis aims to assess a No-Effect reference value for both radiological and chemical aspects of uranium, leading to the determination of the so-called PNEC of the element $U$ in water (single abiotic component for which chemotoxicity data are available), and the PNEDR for the whole set of radionuclides from uranium families. Indeed, radiological effects are linked to the energy deposited in the target organism, expressed in Gray (Gy). For chronic exposure, this energy is divided by the exposure duration, and becomes a dose rate, expressed in Gy per unit of time.

Two methods may be applied to assess these No-Effect reference values, depending on the quantity and the quality of the available ecotoxicity data: small data sets are treated with the classical Assessment Factor Method (AFM) while larger data sets are used to build Species Sensitivity Distributions.

For uranium as a chemical, the SSD (Fig. 2 top) was built on $\mathrm{EC}_{10}$ s (concentrations related to a change of $10 \%$ in the average level of the endpoint for a particular effect) selected in the open literature. The PNEC, deduced from the $\mathrm{HC}_{5}$ (Hazardous Concentration for $5 \%$ of the species, Table 1) by applying a Safety Factor of 1 considering the representativness of the data, was $3.2 \mu \mathrm{g}(\mathrm{U}) / \mathrm{L}$.

Similarly, a radiological SSD (Fig. 2 bottom) was built on literature values of $\mathrm{EDR}_{10}$ (doses rate related to a change of $10 \%$ in the average level of the endpoint for a particular effect). The PNEDR, deduced from the $\mathrm{HDR}_{5}$ (Hazardous Dose Rate for $5 \%$ of the species, Table 1) by applying a Safety Factor of 5 and rounding down [10], was $10 \mu \mathrm{G} / \mathrm{h}$. 


\begin{tabular}{|c|c|c|c|c|c|c|c|c|c|c|c|c|}
\hline AIR & & & & & & & inhalation & & & inhalation & inhalation & inhalation \\
\hline WATER & direct & direct & direct & & direct & direct & direct & direct & direct & direct & ingestion & ingestion \\
\hline \multicolumn{13}{|l|}{ SEDIMENT } \\
\hline & $\begin{array}{l}\text { Midge } \\
\text { larvae }\end{array}$ & & & & & & & ingestion & & & & \\
\hline & ingestion & Algae & & & ingestion & ingestion & & & & & & \\
\hline & & & $\begin{array}{l}\text { Water } \\
\text { milfoil }\end{array}$ & & & & & & & & & \\
\hline & & & & Pine & & & & & & & & \\
\hline & & & & & $\begin{array}{l}\text { Water } \\
\text { flea }\end{array}$ & & & & & & & \\
\hline & & & & & & $\begin{array}{l}\text { Swan } \\
\text { mussel }\end{array}$ & & & & & & ingestion \\
\hline & & & & & & & Mayfly & & ingestion & ingestion & & \\
\hline & & & & & & & & $\begin{array}{l}\text { Roach/ } \\
\text { carp }\end{array}$ & & & & \\
\hline & & & & & & & & & $\begin{array}{l}\text { Perch/ } \\
\text { catfish }\end{array}$ & & & \\
\hline & & & & & & & & & & Frog & ingestion & \\
\hline & & & & & & & & & & & Mallard & \\
\hline & & & & & & & & & & & & Muskrat \\
\hline Legend : & $\begin{array}{l}\text { EXPC } \\
\text { Ref } \\
\text { Tran }\end{array}$ & $\begin{array}{l}\text { RE MEDIUN } \\
\text { nce org } \\
\text { pathway ! }\end{array}$ & $\begin{array}{l}\text { sm } \\
\text { ng to interm }\end{array}$ & oosure & & & $\begin{array}{l}\text { External exp } \\
\text { External exp }\end{array}$ & $\begin{array}{l}\text { sure to a me } \\
\text { sure at the i }\end{array}$ & ium & en two medi & & \\
\hline
\end{tabular}

Figure 1. Theoretical conceptual matrix of internal and external exposure pathways and associated processes for living organisms representative of freshwater ecosystem structure and functioning.

Table 1. No Effect reference values related to uranium ecotoxicity.

\begin{tabular}{|l|c|c|c|c|}
\hline Exposure & $\begin{array}{c}\text { Data number } \\
\text { (geometric mean number) }\end{array}$ & Species number & Reference value & $\begin{array}{c}\text { Confidence interval } \\
95 \%\end{array}$ \\
\hline Chronic & $66(20)$ & 14 & $\mathrm{HDR}_{5}: 98 \mu \mathrm{Gy} / \mathrm{h}$ & $23-497 \mu \mathrm{Gy} / \mathrm{h}$ \\
\hline Chronic & $29(12)$ & 8 & $\mathrm{HC}_{5}: 3.2 \mu \mathrm{g} / \mathrm{L}$ & $0.57-23 \mu \mathrm{g} / \mathrm{L}$ \\
\hline
\end{tabular}

To remain consistent with the chemical approach at a screening stage, the PNEDR is used to backcalculate a PNEC (in Bq/L, Bq/kg fresh weight, Bq $/ \mathrm{m}^{3}$ ), applying the following set of equations.

$$
\begin{aligned}
P N E C_{\text {medium }}(i, o) & =\frac{P N E D R}{O F_{\text {medium }}(o) \cdot D C C_{\text {medium,ext }}(i, o)+T A G_{\text {medium }}(i, o) \cdot D C C_{\text {int }}(i, o)} \\
P N E C_{\text {medium }}(i) & =\min _{o}\left[P N E C_{\text {medium }}(i, o)\right]
\end{aligned}
$$

where

medium is the abiotic exposure compartment (air, water, sediment)

$\mathrm{PNEC}_{\text {medium }}(\mathrm{i}, \mathrm{o})[\mathrm{Bq} / \mathrm{L}$ or $\mathrm{Bq} / \mathrm{kg}]$ is the medium No-Effect concentration for radionuclide $\mathrm{i}$, determined from organism o;

$\mathrm{OF}_{\text {medium }}(\mathrm{o})$ is the occupancy factor of medium by organism o (time fraction spent by organism o in medium);

$\mathrm{DCC}_{\text {medium,ext } / \text { int }}(\mathrm{i}, \mathrm{o})[\mu \mathrm{Gy} / \mathrm{h}$ per $\mathrm{Bq} / \mathrm{L}$ or $\mathrm{Bq} / \mathrm{kg}]$ is the dose conversion coefficient related to the external/internal exposure of organism o to radionuclide $\mathrm{i}$;

$\mathrm{TAG}_{\text {medium }}(\mathrm{i}, \mathrm{o})[\mathrm{Bq} / \mathrm{kg}$ per $\mathrm{Bq} / \mathrm{L}$ or $\mathrm{Bq} / \mathrm{kg}]$ is the aggregated transfer coefficient of radionuclide $\mathrm{i}$ for organism o in medium. 


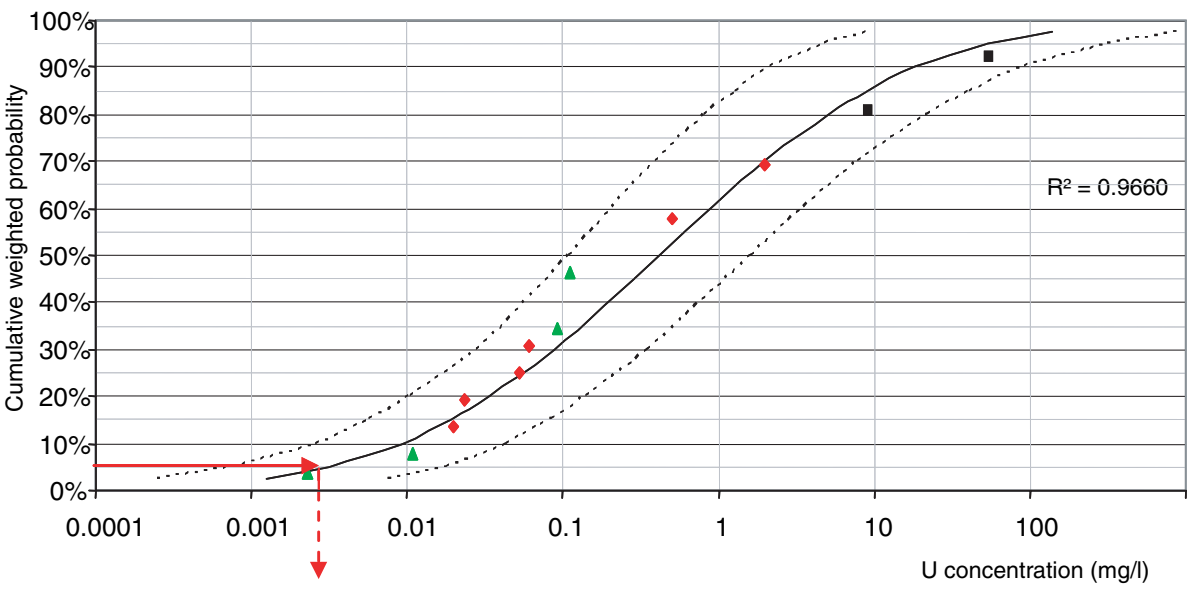

$\mathrm{HC}_{5}$

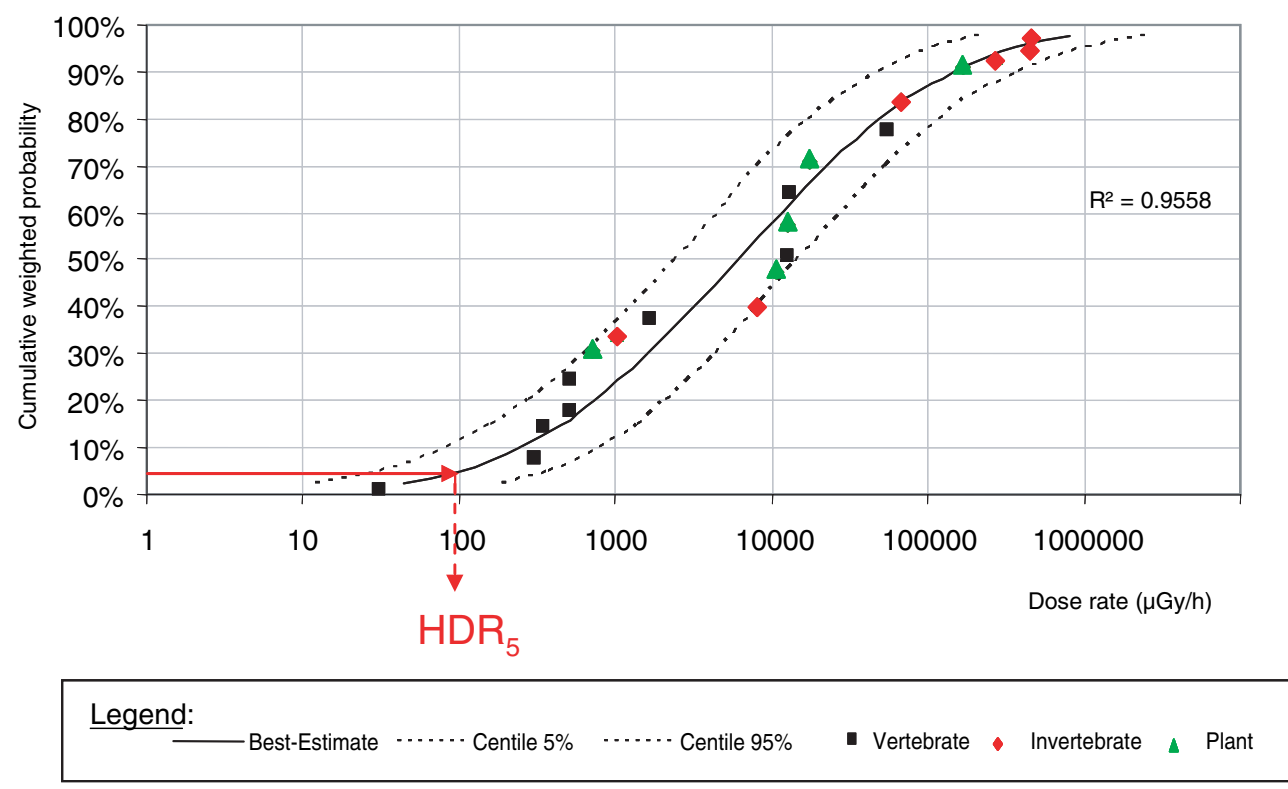

Figure 2. Species Sensitivity Distributions on ecotoxicity data related to uranium (top: chemical data; bottom: radiological data).

\section{STEP 3: EXPOSURE ANALYSIS}

For chemicals, the method requires only $U$ concentrations in water, expressed in mg/L. For radionuclides, water, sediment and air concentrations may be used, expressed respectively in $\mathrm{Bq} / \mathrm{L}$, $\mathrm{Bq} / \mathrm{kg} \mathrm{w} . \mathrm{w}$ and $\mathrm{Bq} / \mathrm{m}^{3}$. These concentrations are called PEC, Predicted Environmental Concentrations. While measurements are obviously preferable but are not always available, modelling may be required to estimate uranium levels in certain situation, applying the $\mathrm{Kd}$ approach or isotope ratios for example. Furthermore, it is important to consider the chemical and radiological natural background of uranium, in order to discriminate total or added risk. This requires the definition of the natural background level, associated with a reference area void of anthropogenic influence, to be subtracted from measured or modelled data. 


\section{STEP 4: RISK CHARACTERISATION}

The first approach consists of the calculation of a simple risk index, corresponding to the ratio between two punctual values, the PEC and the PNEC, and that for chemicals as well as for radionuclides.

If this risk index is significant, i.e. higher than the unity, a more refined approach is applied, using a probabilistic comparison of the PEC and PNEC statistical distributions, as illustrated by Fig. 3.

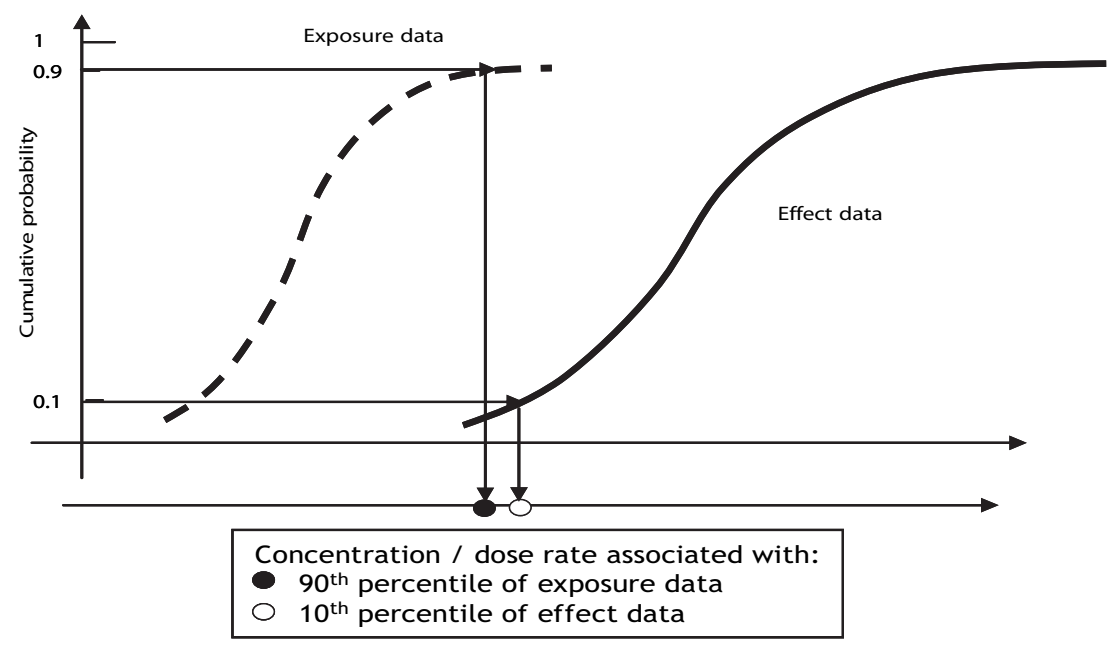

Figure 3. One method for probabilistic comparison of exposure and effect ecotoxicity data.

\section{CONCLUSIONS}

In theory, the four-step ERA methodology can be applied in parallel for assessing both the chemical and radiological risks to ecosystems due to uranium releases. It is currently being tested on case studies. The first application was realized in the framework of the Pluralist Expert Group related to former French ore mining sites that the authors thank for fruitful discussions. This study proved that the approach is operational, but some difficulties that need further investigations were met, mainly concerning the four following aspects:

- how to assess representative background concentrations for elements that have also a natural origin;

- how to deal with radioactive decay equilibria;

- how to deal with censored data sets;

- how to deal with missing transfer factors or outlier values.

\section{References}

[1] European Commission (EC), 2003. Technical Guidance Document on Risk Assessment, Part II. 328 p. Office for Official Publications of the European Communities, Luxembourg.

[2] J. Garnier-Laplace,. C. Della-Vedova, R. Gilbin, D. Copplestone, J. Hingston and P. Ciffroy,. Environ. Sci.\&Techno., 40 (2006), 6498-6505.

[3] R.A. Van Dam, C.L. Humphrey and P. Martin. Toxicol, 181-182 (2002), 505-515.

[4] M.J. Peterson, J.G. Smith, G.R. Southworth, M.G. Ryonand and G.K. Eddlemon. Environ. Monit. Assess., 74 (2002) 193-208.

[5] M. Fan, T. Thongsri, L. Axe and T.A. Tyson. Chemosphere, 60 (2004), 111-125.

[6] R.F. Platford and S.R. Joshi. Health Phys. 54 (1998), 63-68. 
[7] P.A. Thomas. Health Phys. 78 (2000), 614-624.

[8] S.R. Jones, D. Patton, D. Copplestone, S. Norris and P. O'Sullivan. J. Environ. Radioactivity 66 (2003), 89-119.

[9] K. Beaugelin-Seiller, J. Garnier-Laplace, R. Gilbin, C. Adam. American Institute of Physics Conference Proceedings Series (submitted).

[10] Beresford, N., J. Brown, D. Copplestone, J. Garnier-Laplace, B. Howard, C.M. Larsson, D. Oughton, G. Pröhl and I. Zinger, 2007. D-ERICA: An INTEGRATED APPROACH to the assessment and management of environmental risks from ionising radiation. ERICA EC Project Contract FI6R-CT-2004-508847.

[11] J. Garnier-Laplace, D. Copplestone, R. Gilbin, P. Ciffroy, M. Gilek, A. Aguero, M. Bjork,D. Oughthon, A. Jaworska, C.M. Larsson and J. Hingston. J. Environ. Radioactivity (ERICA special Issue), in press. 